Instructions for authors, subscriptions and further details:

http://brac.hipatiapress.com

\title{
La Performance y los Laboratorios de la Utopía: Oskar Schlemmer y la Creación de la Noción de Performance Maisa Navarro ${ }^{1}$, Angélica Camerino ${ }^{1}$
}

1) Universidad de La Laguna. (Spain)

Date of publication: June $3^{\text {rd }}, 2019$

Edition period: February 2019 - June 2019

To cite this article: Navarro, M. y Camerino, A. (2019). La Performance y los Laboratorios de la Utopía: Oskar Schlemmer y la Creación de la Noción de Performance. Barcelona, Research, Art, Creation, 7(2) 157-186. doi: 10.17583/brac.2019.3498

To link this article: http://dx.doi.org/10.17583/brac.2019.3498

PLEASE SCROLL DOWN FOR ARTICLE

The terms and conditions of use are related to the Open Journal System and to Creative Commons Attribution License (CC-BY). 
BRAC - Barcelona Research Art Creation. Vol. 7 No. 2, June 2019, pp. $157-186$

\section{The Performance and Laboratories of Utopia: Oskar Schlemmer and the Creation of the Notion of Performance}

María Isabel (Maisa) Navarro Segura, Angélica Camerino Parra. Universidad de La Laguna. (Spain)

(Received: 9 May 2018; Accepted: 14 April 2019; Published: 3 June 2019)

\section{Abstract}

The main emphasis of the article is on the origins of performative manifestations until they reached a conscious conceptual development with repercussions on contemporary artistic practices. Here we will see how the figure of Oskar Schlemmer, who had started as an artist in the visual arts, was gradually metamorphosed until concreting performative and action experimentations that carried out representative expressions of the utopian laboratories within the vanguards of the first half of the twentieth century; thus contributing to the creation of the notion of performances with a wide and rich possibility of using materials and with a conceptual depth of great depth in constant relation with the most groundbreaking philosophical currents of the time. In addition, he processed and carried out, alone or with the collaboration of several artists, all the known modalities of creative expressions that occurred in parallel with the technological development. And to this was added the research component on the body, human psyche, biocentrism, color, materials, music, lighting and prosthetics, among other points of interest, and on which will delve into the present work.

Keywords: performance, Oskar Schlemmer, utopia, action

2019 Hipatia Press

ISSN: 2014-8992

DOI: $10.17583 /$ brac. 2019.3498
UNIVERS ITAT ${ }_{D E}$ BARCELONA
Hipatia Press

www.hipatiapress.com

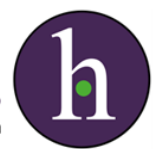


BRAC - Barcelona Research Art Creation. Vol. 7 No. 2, June 2019, pp. $157-186$

\section{La Performance y los Laboratorios de la Utopía: Oskar Schlemmer y la Creación de la Noción de Performance}

Maria Isabel (Maisa) Navarro Segura, Angélica Camerino Parra. Universidad de La Laguna. (España)

(Recibido: 9 mayo 2018; Aceptado: 14 abril 2019; Publicado: 3 junio 2019)

\section{Resumen}

El énfasis principal del artículo se sitúa en los orígenes de las manifestaciones performativas hasta que alcanzaron un desarrollo conceptual consciente con repercusiones en las prácticas artísticas contemporáneas. Aquí veremos cómo la figura de Oskar Schlemmer, quien se había iniciado como artista en la plástica, poco a poco fue metamorfoseándose hasta concretar experimentaciones performativas y de acción que llevaron a cabo expresiones representativas de los laboratorios utópicos dentro de las vanguardias de la primera mitad del siglo XX; contribuyendo así a la creación de la noción de performances con una amplia y rica posibilidad de uso de materiales y con un fondo conceptual de gran profundidad en constante relación con las corrientes filosóficas más rompedoras de la época. Además, procesó y llevó a cabo, en solitario o con la colaboración de varios artistas, todas las modalidades conocidas de expresiones creativas que se produjeron paralelamente al desarrollo tecnológico. Y a ello se añadió la componente de investigación sobre el cuerpo, psique humana, el biocentrismo, el color, los materiales, la música, la iluminación y la prostética, entre otros puntos de interés, y sobre los que se ahondará en el presente trabajo.

Palabras clave: performance, Oskar Schlemmer, utopía, acción 


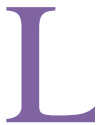

a contribución más importante de los creadores pioneros fue la identificación de la noción de la acción como un concepto abstracto cuyas fronteras son comunes a la danza, las artes teatrales, la vocalización poética, la ficción estética, las improvisaciones gestuales y las acciones sin relato. Distintas aportaciones selectivamente escogidas permiten reconocer la primera acción escénica sin relato en las actuaciones de Loïe Fuller, la realidad física del cuerpo liberada de convenciones en Saint-Point, la noción del objeto escénico animado o el concepto actoral presentado en la obra de Mayakovski, y la reivindicación de la vida como el acontecimiento teatral por excelencia personificado en las experiencias de una constelación de mujeres creadoras que desde la danza o la acción teatral invirtieron el sentido de la noción actor-espectador.

Al contemplar las aportaciones femeninas a las artes de la acción, en el contexto de las vanguardias desde el cambio de siglo y en los periodos anterior y posterior a la Primera Guerra Mundial sobresale de manera llamativa la revolución provocada por una serie de figuras individuales que, aunque relacionadas con algunas corrientes estéticas y grupos artísticos, contribuyeron a identificar los aspectos esenciales de la transformación radical del teatro, la danza y la expresión corporal como un arte de la acción.

Merecen considerarse preferentemente dos figuras por crear, sin precedentes ni relación directa con movimientos artísticos asociados, un nuevo género, que se vinculó a sus respectivas experiencias vitales: Loïe Fuller y Valentine de Saint-Point. Ambas figuras permiten contemplar variados procesos que prefiguran la inmediata relación entre teatro, danza, acción poética y performance. En algunos de estos ejemplos pioneros podemos comprobar la manera en la que sus autoras evolucionaron desde la construcción de un drama representado, estudiaron por primera vez el control de las acciones a través de un proyecto (Fuller) o a través del proceso de liberación personal expresado en el desnudo (Saint-Point), o también, en ambos casos, reivindicando la improvisación como procedimiento de verismo expresivo e inconsciente. Es preciso mencionar esta breve genealogía de experiencias singulares en las que la danza contemporánea es el más importante laboratorio conceptual de las artes y de su teoría. Se trata de la invención de una forma de expresión corporal diferenciada del ballet, y asimilable a la danza contemporánea en la que son los instintos y los gestos de expresión individual los que prevalecen.

En este sentido, es importante destacar cómo Valentine de Saint-Point introduce la noción de arte total a través de su obra Métachorie, que cobró 
forma a través de su ejecución a partir de partituras de Erik Satie, Claude Debussy, Maurice Ravel y Daniel Chennevière como danzas libres pero sujetas a proyectos dibujados ...escribo mi danza gráficamente como una partitura de orquesta (Sina, 2011). Los movimientos artísticos del simbolismo, el futurismo y el expresionismo, aspiraban a la fusión del ser humano con el universo y potenciaron la unión de todas las manifestaciones según los objetivos del romanticismo. Se proponían alcanzar un mundo sublime de sensaciones, y reconocieron en las artes de la escena la propia representación de la vida (Pastor Prada, 2012). El expresionismo y el futurismo se interesaron por diferentes aspectos a las artes de la escena. En particular, el teatro de Mayakovski introduce la autonomía del objeto, que, al actuar como los representados en la pintura metafísica, se transforman en hechos comunicativos, fragmentos de la realidad (véase Imagen 1).

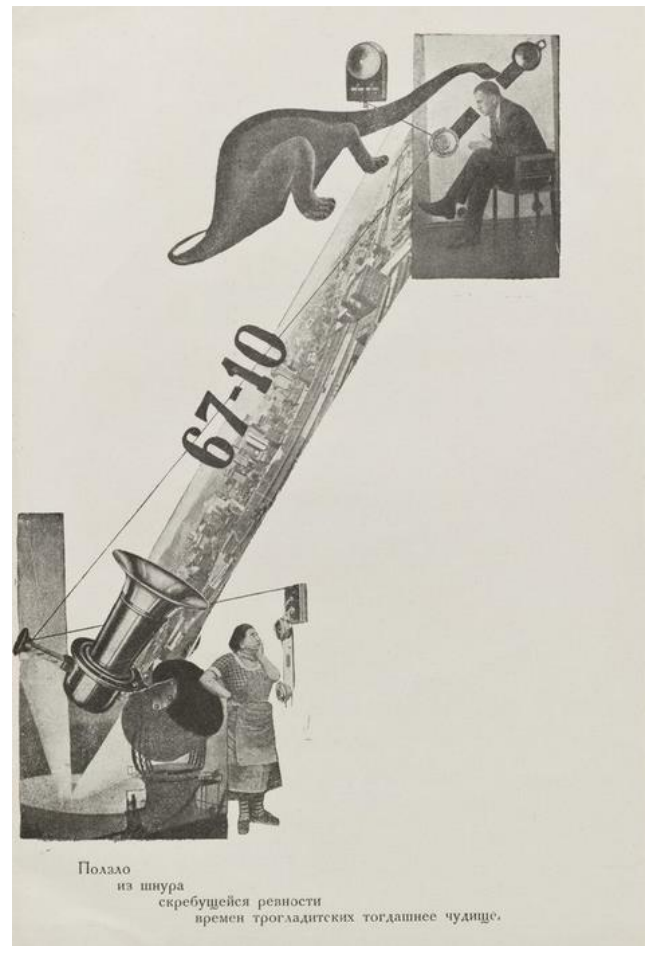

Imagen 1. Rodchenko, A. (1923). Vladímir Mayakovsky. Pro Eto. [Fotomontaje, gelatina de plata, 23,7 × 16,2 cm.] Recuperado de http://bit.ly/30gR39W 
La ficción más reveladora es su obra La revolución de los objetos (1913), cuyo título fue registrado oficialmente por error con el nombre de su autor (Mayakovski, 1972). A pesar del rechazo del público en su representación, refleja la idea del nuevo concepto de escena, al imaginar una realidad en la que los objetos proceden contra las personas en venganza por sus acciones. La experiencia precoz de construir periódicos parlantes para divulgar las noticias en los momentos anteriores a la revolución y la necesidad de contar con artes escénicas al servicio de la pedagogía colectiva suscitaron la recuperación de todas las formas de acción de origen popular, tales como las fiestas y celebraciones, los teatros ambulantes, los bailes, los saltimbanquis, el circo, entre otros (Enrile Arrate, 2016).

Las relaciones mantenidas por los profesores de la Bauhaus con artistas y activistas de la revolución rusa, y particularmente tras la llegada de Hannes Meyer a la dirección de la Escuela en Dessau (1926), explican el interés que alcanzaron ciertas fórmulas teatrales de gran éxito en el proceso de la revolución.

\section{Oskar Schlemmer y la Creación de la Noción de Performance}

En tres décadas, desde el cambio de siglo hasta los años 1920, las artes de la escena llevaron a cabo una transformación intensa en sus fundamentos y en su significado como disciplina. Laboratorio creativo, método técnico y pedagógico, y concepto estético de las artes audiovisuales en este momento, los procesos vividos en esta evolución permiten reconocer en la figura de Oskar Schlemmer el origen de la idea de performance en su dimensión de noción conceptual y una referencia seminal en el desarrollo de las artes de la acción (véase Imagen 2).

No fue casualidad que la recuperación de la figura de Schlemmer conociera una relevancia internacional en los años 60, al publicarse algunas recopilaciones en Estados Unidos y algunos testimonios en Francia, y especialmente tras la publicación de sus textos contenidos en sus diarios y en algunas publicaciones que no habían logrado difusión hasta entonces, así como en sus cuadernos de apuntes relativos a sus actividades de enseñanza en la Bauhaus.

En 1958, Tut Schlemmer, su viuda, había publicado en Munich la recopilación selectiva de textos y también una selección de cartas intercambiadas por Oskar con ella misma y con personajes relevantes de los procesos que vivió el desarrollo de su obra en los momentos más significativos de su vida, especialmente durante la Primera Guerra Mundial 
y desde luego, durante las distintas fases de su vida en la Bauhaus, que permitieron un desarrollo inusitado con implicaciones en la pedagogía, la escenografía, música, coreografía, diseño, acción teatral, producción cooperativa, fotografía escénica,... (Schlemmer, 1958). Este reconocimiento tenía mucho que ver con la implicación que en la escena conceptual estadounidense tuvo la experiencia en Black Mountain a través de la figura de Xanti Schawinsky, primero estudiante y finalmente colaborador en la sección de Teatro en la Bauhaus, trasladado a Estados Unidos por invitación de László Moholy-Nagy para formar parte del núcleo de profesores en la escuela fundada en Carolina del Norte. Como es bien conocido, Black Mountain fue el escenario de las primeras experiencias de la performance, que habría de convertirse en la actividad más notoria en las décadas que siguieron hasta la actualidad. Entonces comenzó la valoración de las aportaciones de Oskar Schlemmer y sus relaciones con las experiencias realizadas en la Bauhaus, que se divulgaron por primera vez en lengua inglesa a través de una insólita publicación del Bauhausbücher $n^{\circ} 4$ (véase Imagen 3) en Estados Unidos con introducción de Gropius y traducción de Wensinger así como los textos originales de Oskar Schlemmer, a los que se añaden colaboraciones de László Moholy-Nagy y Farkas Molnár (Gropius y Wensinger, 1961).
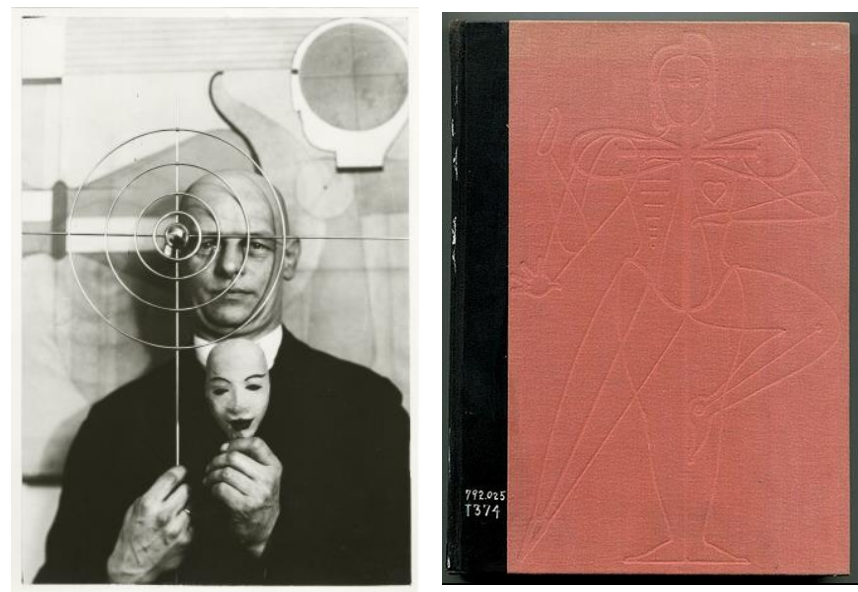

Imagen 2. Foto Klein (1931). Oskar Schlemmer. Recuperado de https://thecharnelhouse.org/tag/oskar-schlemmer/

Imagen 3. Bauhausbücher 4 (1961). Edición estadounidense.

Recuperado de https://www.abebooks.com/booksearch/author/gropius,-walter-editor-translated-by-arthur-swensinger-? 
La revolución que condujo a la definición de la noción de escenografía tuvo todo que ver con el movimiento Mundo del arte (1895-1917) que recorrió Europa a través de la notoriedad de sus principales impulsores Serguéi Diáguilev y Léon Bakst (AA. VV., 2011), que establecieron un vínculo necesario entre las artes y el teatro tradicional produciendo la primera versión de una unidad de las artes en el mundo escénico. A través de las revistas y de sus actividades públicas, que incluyeron exposiciones de artistas plásticos y contribuciones críticas sobre las artes, reclamaron la integración de todas las manifestaciones identificando como elementos constitutivos de la escena la música, la coreografía, el trabajo de los actores, decorados y vestuario, junto con la dirección escénica. La visión sintética de las artes se acompañó de una aspiración a realizar una autoformación recuperando periodos de historia de la cultura desaparecidos proponiendo como método la visión romántica de la sintonía entre literatura, música, pintura, filosofía, historia cultural, ... Como tantas expresiones de su tiempo, el movimiento Mundo del arte, profundamente contradictorio, era una manifestación revivalista interesada en los descubrimientos de la arqueología y en la reconstrucción de estéticas desaparecidas. Sin embargo, la renovación de la escena, la creación de géneros autónomos, la expresión individual a través de la improvisación, se introdujeron en este proceso. La investigación previa y los procesos de documentación gráfica basados en nuevas disciplinas asociadas a la creación escénica —entre ellos la anatomía artística-, se transformaron a la luz del nuevo sentido estético en obras plásticas, que alcanzaron difusión a través de las revistas asociadas al movimiento.

De ahí derivó la corriente expresionista que animó la escena de Weimar durante el periodo inicial de la dirección de Gropius (1919-23), que invitó a Lothar Schreyer a dirigir el taller de teatro en 1921. Venía precedido por su actividad teatral vinculada al colectivo expresionista, dado que había fundado en 1918 la compañía Sturm-Bühne con Herwarth Walden director de la galería y revista homónima que junto con la revista Aktion reunía los colectivos artísticos más comprometidos con la revolución social y de las formas de vida en la inmediata posguerra. En sus actividades se desarrolló la versión expresionista de la danza, que tuvo en Mary Wigman a su figura más notoria.

La reforma de la escena fue una realidad que alcanzó un desarrollo considerable mientras se extendía por Europa el interés por la nueva noción integrada de las artes que permitía transmitir la ilusión de volver a la vida episodios de otras culturas y hacer realidad relatos de ficción. Sin embargo, 
el final de este concepto, coincidente con la proclamación de la Revolución Soviética en 1917 dio lugar a una de las experiencias insólitas entremezclada con la revolución vanguardista desarrollada en la Bauhaus. El exilio de algunos de sus miembros destacados en diferentes lugares de Europa suscitó una influencia evidente en los sectores de la escena, la danza, la música y las artes plásticas, especialmente en París, que reunió una significativa colonia de artistas rusos, y también en Alemania, donde habría de producirse una rápida evolución de los principales conceptos prefigurados por este movimiento.

\section{Oskar Schlemmer: el Sentido Dramático de la Existencia y los Espectáculos de la Acción}

El pintor Oskar Schlemmer experimentó la revolución completa del siglo veinte en su propia trayectoria. Se transfiguró en una versión desconocida de creador inter-media, escenógrafo, danzarín, performer, diseñador de indumentaria, de la escena, pedagogo, ... Resulta reveladora su conocida sentencia: Soy demasiado moderno para pintar lienzos... Aquí puedo ser nuevo, abstracto, todo (Schlemmer, 1987, pp. 78-79).

Desde su etapa juvenil se sintió atraído por las posibilidades del desarrollo de la acción como expresión de una obra musical, tal como recoge la carta que dirigió a su amigo, el pintor Otto Meyer en enero de 1913, en la que cuenta que asistió a una modalidad de concierto del Melodrama de Arnold Schönberg recitado por una ejecutante, que le llevó a solicitar al compositor música moderna para su interpretación mediante la danza (véase Imagen 4).

Al incorporarse a filas en 1914, simultaneó sus relatos sobre el combate, las convalecencias en hospitales de campaña y las lecturas, que consideraba premonitorias y parte integrante de sus estudios sobre los opuestos y el doble, hilo argumental de todos sus escritos y su actividad escénica. De esta primera etapa es la serie de figuras humanas que expresan la imagen de un Pobre soldado (1914), esquematizada forma de un ser anónimo. Quiero dar forma a todo lo humano, a todo lo susceptible de ser vivido (Diario, 1915).

$\mathrm{Al}$ comienzo de la guerra, los efectos devastadores de las armas mecanizadas provistas de metralla provocaron inmediatamente un efecto devastador en los jóvenes soldados movilizados que sobrevivían a importantes mutilaciones de sus miembros, pero que además en muchos casos quedaban desfigurados de manera tan trágica que les impedía llevar una vida normal (véase Imagen 5). En Londres, el escultor Francis Derwent 
Wood, que trabajaba en el hospital de Wandsworth, creó en 1916 un servicio como parte de las actividades del denominado Departamento de desfiguración facial, que fue apodado por los soldados la Tienda de narices de estaño. Se trataba de proporcionar una reconstrucción facial a través del trabajo artístico para lesiones que entonces no podía resolver la cirugía reparadora. También creó un servicio de este tipo en París la Norteamericana Anna Coleman Ladd siguiendo este procedimiento de reconstrucción mediante un metal protésico y ligero (véase Imagen 5).
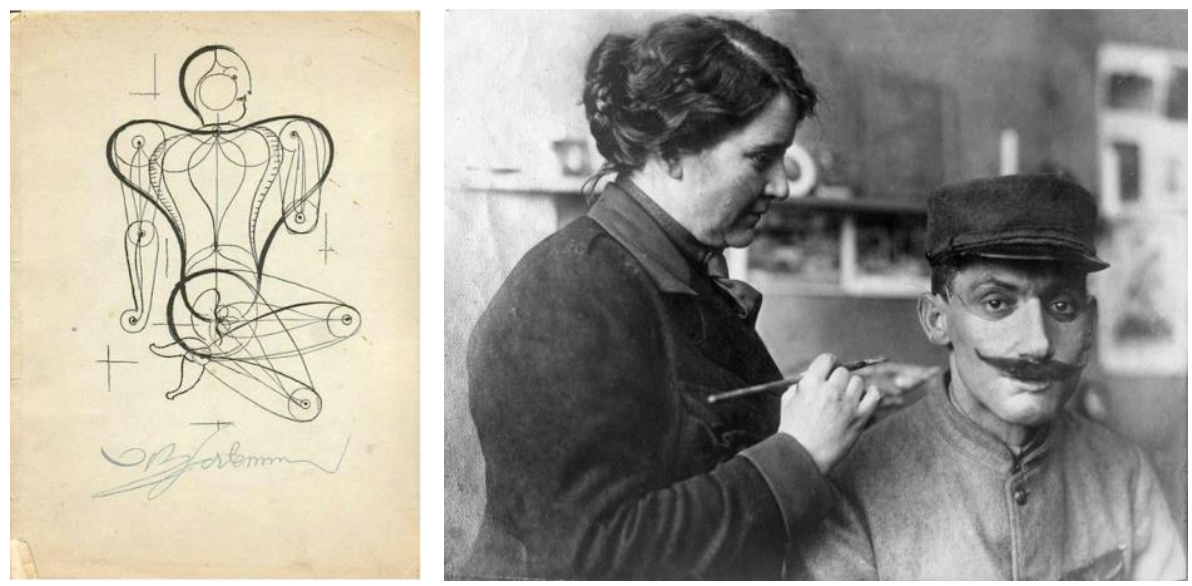

Imagen 4. Schlemmer, O. (1919-20). Proyecto de figuras. [Litografía sobre papel, 41 x $31 \mathrm{~cm}$.]. Carpeta Die Schaffenden, 1921. Col. Raman Schlemmer. Reimpreso de Bauhaus 1919-1933: da Klee a Kandinsky, da Gropius a Mies van der Rohe (pág. 128) [Catálogo de la exposición]. M. De Michelis y A. Kohlmeyer A. (ed.). (1996), Milán Fondazione Antonio Mazzotta.

Imagen 5. Documentación de reconstrucción facial de soldados de la Primera Guerra Mundial (1918). Colección Ana Coleman. Archives of American Art, Smithsonian Institution. Recuperado de https://www.aaa.si.edu/collections/annacoleman-ladd-papers-10600/series-7/box-3-folder-2

En octubre de ese año Schlemmer definió su primera visión de geometría asociada a la figura humana mecanicista:

El cuadrado de la caja torácica, /el círculo del vientre, /el cilindro del cuello,/ los cilindros de los brazos y las piernas, /los círculos de las articulaciones de los codos / las rodillas, los hombros, los nudillos /los círculos de la cabeza, de los ojos,/ el triángulo de la nariz,/ la línea que une el corazón con el cerebro, /la línea que une la cara con el objeto mirado,/ el ornamento que se forma entre el cuerpo y/ el mundo 
exterior, simbolizando la relación /del primero [el cuerpo] /con lo Segundo [el mundo]. (Schlemmer, 1987, p. 32)

La danza, que es dionisíaca y completamente emocional en su origen, se convierte en apolínea en su forma final, un símbolo de equilibrio de opuestos. El Ballet triádico... se esfuerza por conseguir la desmaterialización. [...] Primero surgió el vestuario, los figurines. Después, la búsqueda de la música que mejor les correspondiera. Música y figurines, juntos, llevaron a la danza. Este fue el proceso seguido por Schlemmer en sus obras.

La orientación hacia la danza se produjo en plena guerra por una circunstancia azarosa debida a una actividad benéfica para su regimiento en 1916. A este momento corresponde la primera versión del futuro Ballet Triádico, como muestran los dibujos de su diario (véase Imagen 6). La ejecución de un proyecto de ballet propio le permitió experimentar su propia condición de ejecutante, que le llevó a considerar sus propias posibilidades de experimentación futuras: las innovaciones decisivas van a partir de este sector menor, pero más libre, del arte escénico (11 de febrero de 1918), escribió después. La pantomima y el ballet están libres del peso de la historia.

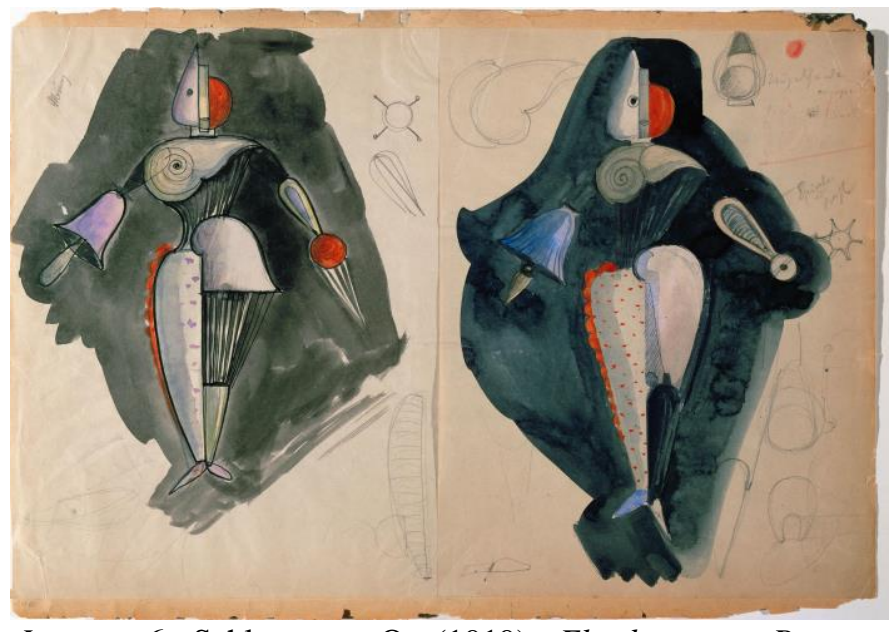

Imagen 6. Schlemmer, O. (1919). El abstracto. Bocetos preliminares para el ballet triádico. [Acuarela, lápiz y tinta sobre papel transparente]. Recuperado de https://www.reprodart.com/a/schlemmeroskar/designfortriadicballet22-1.html 
La referencia a la importancia de la danza se traduce en un argumento filosófico mediante alusiones a Kierkegaard en su diario, a pesar de que fue Nietzsche quien le dedicó numerosos pasajes en su obra, y la máxima ...el mundo pertenece al bailarín. Las cualidades temporales compartidas por la música y la danza se expresan a través del cuerpo humano, al que califica de genio erótico.

Schlemmer lee a los románticos y reconoce buscar

... las corrientes subterráneas, la «teoría de lo inconsciente» (19 de agosto de 1918). Lo que aparece con claridad en su balance al final de la guerra es la inutilidad de la estética: Resultado de una exposición: Abismo espantoso entre el arte y el público. Lo que hoy parece peligroso mañana será natural (octubre de 1919). Su diario anuncia entonces el objeto de su trabajo: La representación del hombre continuará siendo la mayor comparación para el artista (noviembre de 1919). (Schlemmer, 1987)

Y hay constantes referencias de su lenguaje traspasado por las lecturas de los textos de Nietzsche sobre la misión de los opuestos en la existencia, en el análisis de la realidad, que alcanzan una expresión visible en el mundo de la danza.

En Nietzsche la danza es definida en tres niveles desde el punto de vista de su sentido estético: sucesivamente, en el primer nivel se relaciona con la música y la poesía como tríada dionisíaca, en el segundo se relaciona con el pensamiento y el lenguaje; finalmente, es la forma de expresión artística de Zaratustra (Watson, 2014).

En la danza también está presente la noción espacial expresada en la geometría...

Estoy interesado también en la geometría que se aplica a la superficie del suelo sobre el que se baila, aunque sólo como una parte y una proyección de la geometría espacial sólida. Estoy trabajando en una geometría similar de los dedos y las teclas en el piano, en un esfuerzo por lograr la identidad (o unidad de movimiento y de forma corporal) y la música. (Schlemmer, 1987, pp. 78-79. Carta a Otto Meyer. Cannstatt, 12 de junio de 1920)

También está presente la obra de Schiller, Cartas sobre la educación estética (1876), en la que desarrolla su elaborada teoría articulada en torno a 
la polaridad entre materia y forma, entre fuerza de la sensibilidad y fuerza de la razón. Esta polaridad se trasciende a través del sentido del juego.

Schlemmer trabaja a partir de ese momento en diversos planos, destacando las dos vertientes intelectuales fundamentales en su proyección como pensador, creador y pedagogo: la propuesta analítica de la disciplina y todas las disciplinas transversalmente integradas en ella, y también la elaboración conceptual de términos que son neologismos relativos a conceptos entonces no desarrollados.

Merece una referencia fundamental la reformulación en sus escritos de la palabra 'gestalt', que podría considerarse equivalente a 'forma'. De ella configura dos variaciones de interés en el proceso teórico que desarrolló durante estos años hasta los años 30: 'gestalten', verbo que implica la acción de producir una forma y el sustantivo 'gestaltung' que se refiere al mismo tiempo a configurar, dar forma, producir una forma, llegar a la forma.

Como ya se ha mencionado, el artista fue llamado en 1920 a la Bauhaus en Weimar para colaborar en las clases de dibujo del desnudo y también con el taller de teatro que tuvo encomendado Schreyer hasta 1923. Inmediatamente Schlemmer se involucró en numerosas actividades que traspasaron la vida de la escuela. Se trataba de convertir la propia actividad cotidiana en una expresión del drama de la existencia dando curso a todas las posibles manifestaciones. Así se introdujeron las fiestas, actuaciones musicales con la creación de la banda de jazz de la escuela, las actuaciones de teatro, pantomimas, ... Luego, a partir de 1923 y hasta 1930 tuvo a su cargo el taller de teatro, que se transformó en teatro experimental a partir de 1926 tras la inauguración del nuevo edificio en Dessau, en el que Gropius había diseñado un espacio escénico en pleno corazón del edificio principal.

Todas las vertientes de la acción tendrán participación en los proyectos que se desarrollan a partir de este momento interrelacionados con actividades festivas. Se evocará la noción de la tragedia clásica mediante la creación de máscaras, la deshumanización se expresará a través de las indumentarias y las prótesis y los zancos provocarán imágenes gigantescas, la risa y lo grotesco se harán presentes en el carnaval. Todo ello mediante recursos sometidos a un riguroso control a través de la puesta en escena planificada con toda clase de recursos visuales, formales, polícromos, lumínicos y sonoros.

Merece destacarse la transformación operada en los rituales de la escuela desde su periodo histórico en Weimar, donde ya existían eventos programados en momentos simbólicos oficiales. Este calendario se vio completamente revolucionado por la introducción de la fiesta como 
mecanismo de estímulo creativo conforme a los escritos de Schiller sobre la educación artística, en los que se reivindica la participación del juego como método esencial de la creación (Schiller, 1990).

Nuevos acontecimientos festivos transformaron los existentes y construyeron un calendario alternativo: la Fiesta de los farolillos o del solsticio de verano (21 de junio), la Fiesta de las cometas (octubre) construyendo inverosímiles artefactos para echarlos al vuelo en las colinas de Weimar, Fiestas de Navidad con denominación pagana, Fiestas de carnaval, ...; también incluían fiestas estacionales y propias de la escuela de manera institucional, y otras que fueron incorporándose más tarde, con carácter mensual: la Lantern Fest - fiesta de las linternas: cortejo nocturno a través de la ciudad- (véase Imagen 7), la fiesta del solsticio, la de las cometas, en las colinas en torno a Weimar, la de los regalos. A estas se añadieron progresivamente una serie de fiestas de carácter temático en Dessau: la Weissen Fest -Fiesta blanca, 2/3 blanco, 1/3 a rayas, a lunares, a cuadros (1926), la Schlagwörterfest —Fiesta de los eslogans (1927)—, la Bart-Nasen-Herzensfest -Fiesta de las barbas, nariz y corazones (Berlín, 1928)_, o la Metallische Fest, _Fiesta metálica o fiesta de las campanas, campanillas y cascabeles (1929).

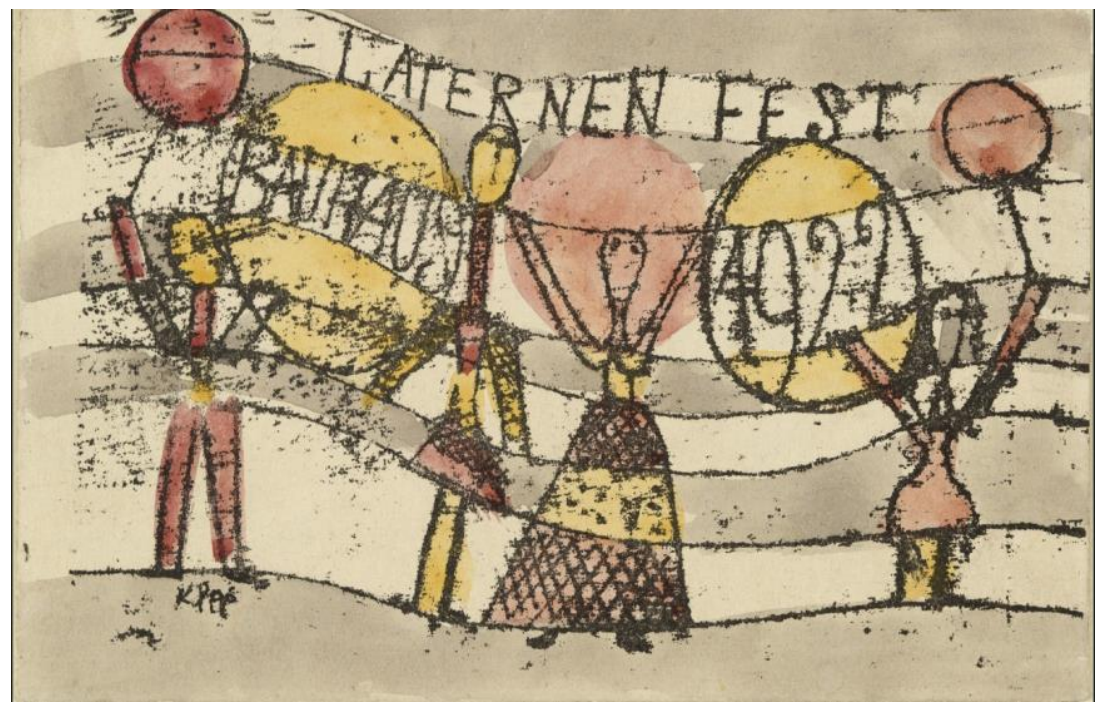

Imagen 7. Klee, P. (1922). Lanternfest. Postal. [Litografía con añadidos de acuarela, $\quad 9 \quad \mathrm{x} \quad 14,3 \quad \mathrm{~cm}] . \quad$ Recuperado de https://www.moma.org/s/ge/collection_ge/artist/artist_id-3130_role1_sov_page-83.html 
La relación de estas actividades festivas con la obra escénica y performativa de Schlemmer merece desatacarse. Algunas fueron obras realizadas ex profeso. Tal fue el caso de la fiesta de carnaval para la que Schlemmer organizó y diseñó el Gabinete de figuras I (1922) inspirándose en la película de Robert Wiene estrenada dos años antes. En esta primera versión se integran elementos icónicos que venía desarrollando en sus apuntes y reflexiones contenidas en el diario, especialmente en su periodo militar durante la Primera Guerra Mundial. De esa época son los primeros bocetos intercalados con sus textos sobre las nociones del arte (véase Imagen 8).

Sus referencias iniciales en el cambio que quería operar en la danza del taller de la Bauhaus hacen referencia al abandono de la expresión y a la adquisición de un método para poner en relación la acción espacial del organismo biológico del actor como un hecho mecánico, "una pantomima bailable" (Schlemmer, 1987, p. 154). Esta propuesta es una de las fases de su evolución desde el teatro antinaturalista, artificial. Sin embargo, el estadio posterior habría de ser lo que calificó como «teatro metafísico» (Schlemmer, 1987, p. 172), dado que el ballet va de lo convencional a lo abstracto. El objetivo que seguir en sus textos del momento es experimentar para provocar un resultado en fase de estudio todavía...

Las preocupaciones teatrales... responden a las consignas y actitudes que mencioné arriba: piezas humorísticas, dadaísmo, experimentos mecánicos, efectos cinematográficos son el furor en este momento. [...] Teatro experimental de nuevo: quiero continuar con la geometría de la danza, usando alfombras con diversos patrones geométricos (tablero de ajedrez, etc.) sobre los cuales bailar. Cada casilla tendrá un número y, durante la danza, alguien irá gritando los números. Un procedimiento similar con los instrumentos musicales (las simples percusiones), y con los colores, el espacio, etcétera. [...] La meta inmediata: descubrir los principios que gobiernan las diferentes áreas: espacio, movimiento, forma, color. (Schlemmer, 1987, pp. 183-186. Carta a Otto Meyer, diciembre de 1925) 


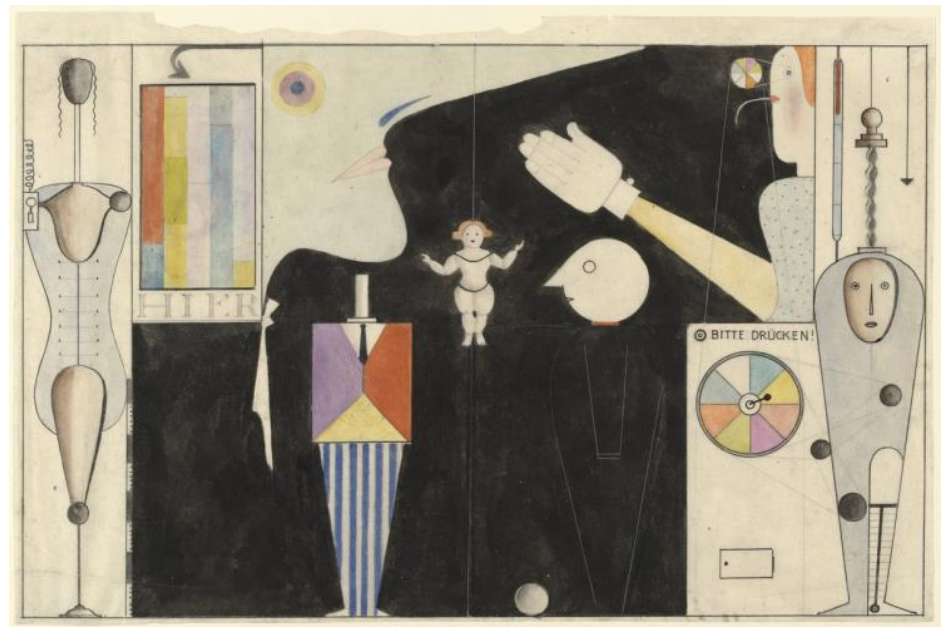

Imagen 8. Schlemmer, O. (1922). Gabinete de figuras (Das figurale Kabinett). [Acuarela, lápiz y tinta sobre papel transparente, 30.8 x $45.1 \mathrm{~cm}$.]. MoMA, The Joan and Lester Avnet Collection. Recuperado de https://www.moma.org/s/ge/collection_ge/artist/artist_id5219_role-1_sov_page-11.html

\section{Schlemmer y la Bauhaus}

Como maestro de la Bauhaus, desarrolló un conjunto variado de roles en la evolución de la escuela en los que se pone de manifiesto el potencial de la propia evolución de las manifestaciones creativas del siglo en el plano teórico, conceptual y de la producción artística. Fue sucesivamente director del taller de pintura mural (1920-22), director del taller de escultura en piedra (1921-29), director del taller de escultura en madera (1922-26) y responsable de la escena de la Bauhaus (1923-29).

En su actividad profesional dejó constancia de su conciencia crítica a través de su diario, en la correspondencia mantenida con su mujer Helena Tutein [Tut Schlemmer] y con su amigo más próximo, el artista Otto Meyer (Schlemmer, 1958), entre otros, aparte de las conferencias y otros textos aparecidos en diversas publicaciones de la escuela. Sus textos más divulgados fueron El hombre y la figura artística (1924) y La escena y la Bauhaus (1926) publicado en el Bauhausbücher $\mathrm{n}^{\circ} 4$ y en la revista de la Bauhaus (Gropius, 1961). 
Los nuevos materiales ofrecen nuevas posibilidades a la producción artística contemporánea según se desprende de sus anotaciones en su diario, en el que menciona las cualidades del vidrio, hierro, cobre, plexiglás... materiales con los que realizó la indumentaria de sus proyectos para la escena (véase Imagen 9).

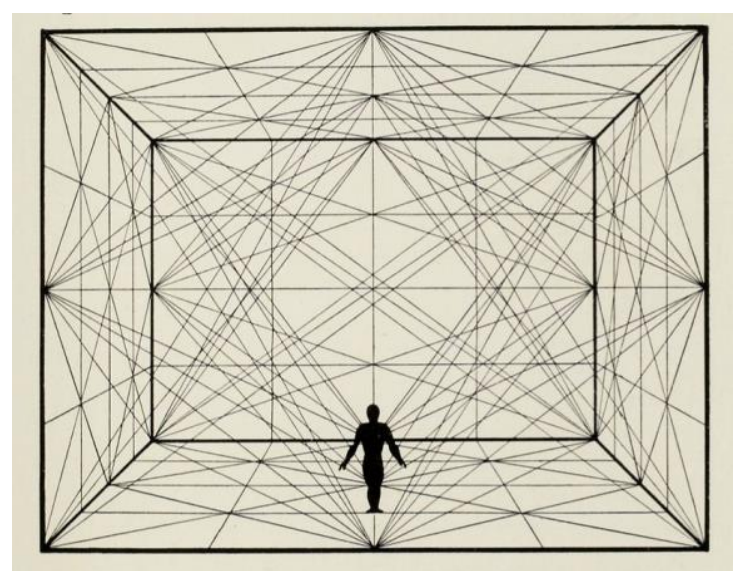

Imagen 9. Schlemmer, O. (1926). Configuración del escenario abstracto. Bauhausbücher 4.

Resulta particularmente interesante su descripción sobre la evolución del proyecto de la escuela, que define como una transformación desde unos ideales iniciales de naturaleza romántica, expresión del rechazo a la mecanización y el materialismo dominantes. Describe sus efectos en el inconsciente colectivo reconocibles en la generalización del misticismo, en el interés hacia fenómenos estéticos exóticos, y las expresiones creativas de la infancia y los alienados. Este episodio, en su etapa posterior, fue contestado por el dadaísmo y sus métodos críticos que ponen en cuestión la irracionalidad dominante mediante procesos de desmontaje y construcciones paradójicas. A su juicio, el periodo que sucede está dominado por la influencia americana, que muestra dos polos de un mismo proceso, la producción de nuevos materiales expresión de su racionalidad y sus bases tecnológicas y científicas: el acero, el hormigón, la electricidad. Y esta potencia creativa conlleva un proceso de abstracción antinaturalista.

$\mathrm{Su}$ producción propia conoció una diversidad llamativa. Inicialmente tuvo una mayor actividad como artista plástico, pintor, escultor, muralista y decorador. Posteriormente amplió sus aplicaciones con obras como decorador y productor de indumentarias por cuenta propia. Al incrementarse 
sus cometidos en la escena se convirtió en escenógrafo, coreógrafo, bailarín, performer, clown, ... (véase Imagen 10).

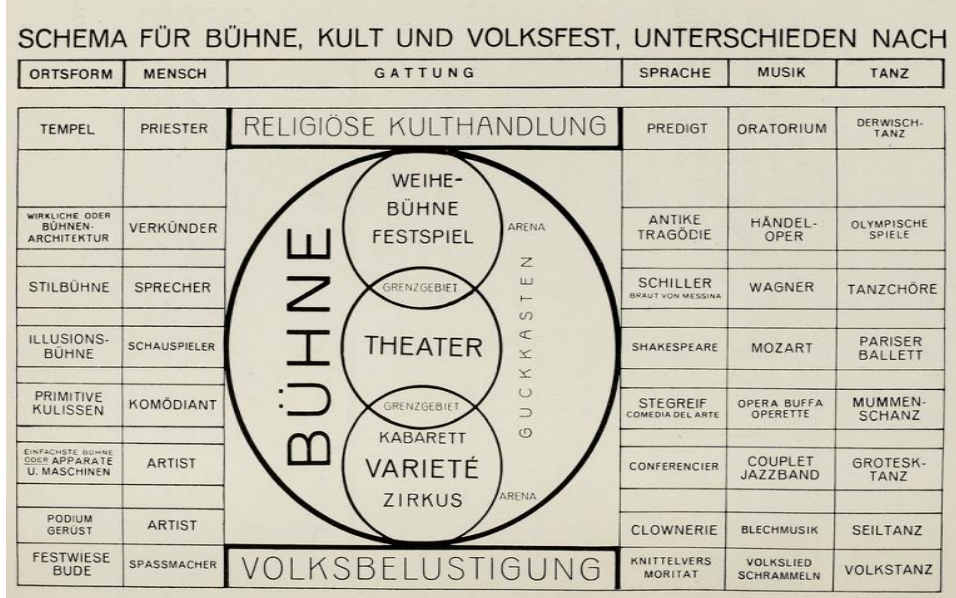

Imagen 10. Schlemmer, O. (1926). Esquema de actividades teatrales. Bauhausbücher $n^{\circ} 4$.

Además, merece destacarse la actividad pedagógica y su producción asociada. El curso Der Mensch —el hombre (1928-29) de la asignatura de dibujo que impartió desde 1921, tomó la figura humana como pretexto de estudio desde numerosas disciplinas en un enfoque conceptual del que consta la imagen reelaborada en distintas aproximaciones de un cuerpo humano y las ciencias de estudio correspondientes (Schlemmer, 1969). Sucesivas versiones de este curso fueron impartidas en Bratislava (el hombre y el espacio), y más tarde en Berlín. El hombre es una totalidad corporal, intelectual y espiritual. Como ser cósmico es el objeto de estudio de la modernidad. La versión final del curso en la etapa de la Bauhaus en Berlín constaba de tres aspectos: formal -expresión gráfica: dibujo y proporciones, leyes del movimiento y coreografía como expresión de la gimnasia, la danza y el teatro-, biológica: aspectos científicos del universo, del hombre, anatomía, fisiología, higiene, los sentidos como la vista y el tacto- y filosófica: estudio de las ideas, con atención a la imaginación y la actividad conceptual, sistemas filosóficos, problemas del espacio y del tiempo, la psique, y además la metafísica (véase Imagen 11). 


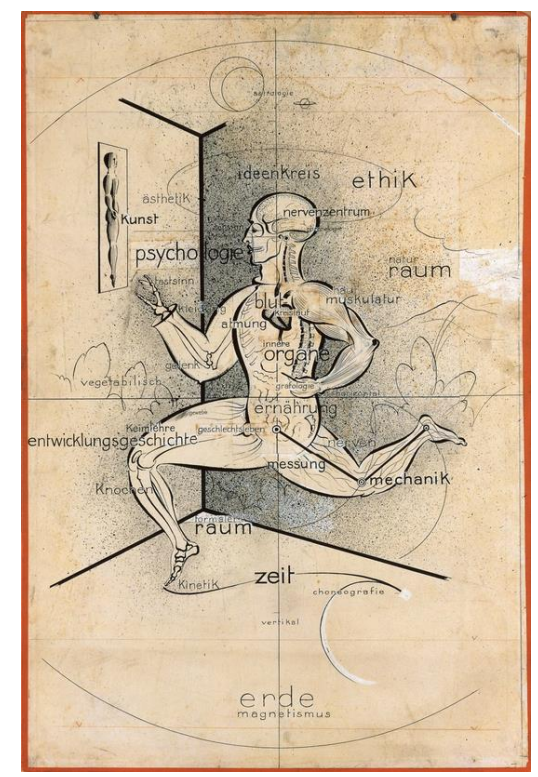

Imagen 11. Schlemmer, O. (1928).

Der Mensch im der Ideenkreis. el hombre en el círculo de las ideas-. [Tinta, lápiz y lápices de colores sobre papel]. Postal de la Bauhaus.

Esta condición compleja de Schlemmer queda bien definida a través de los recuerdos de uno de sus discípulos, Albert Menzel [más tarde Flocon]:

...Pero entonces quién era este Oskar Schlemmer, maestro de ceremonias, ¿pintor, escultor, hombre de teatro y escritor? A mi juicio el maestro (Meister) de la Bauhaus que más dio a la escuela, ha formulado, entre los analistas del espacio artístico - los Klee, Kandinsky, Albers - las visiones más sutiles y las más ricas, y es, para mí, el más excitante de los pintores de la escuela. Además, un maestro escritor y epistolar cuyos escritos son ciertamente la fuente más interesante para el conocimiento del movimiento desordenado y contradictorio llamado Bauhaus. (Flocon, 1987) 


\section{Schlemmer: la Figura Humana, Prótesis y Acción}

Durante el periodo de la Gran Guerra y al finalizar la contienda numerosos artistas plásticos produjeron variadas alusiones al carácter metafísico del objeto. Comenzaron a proliferar también representaciones de figuras protésicas, mecanizadas o imágenes de autómatas. Los cuerpos podían llevarse más allá de sus límites mediante añadidos que prolongaban la figura, incrementando sus cualidades físicas.

Este imaginario procedía, como hemos mencionado, del espectáculo provocado por las horribles mutilaciones de la maquinaria bélica industrializada de la Gran Guerra. La fabricación de toda clase de prótesis fue corriente en todos los países. Pero en esta ocasión, aparte de pérdida de extremidades, fueron particularmente generalizadas las mutilaciones provocadas en los rostros por efecto de la metralla. Además, durante los meses que duró la pandemia de gripe, la vulnerabilidad humana quedó de manifiesto en una proporción desconocida en el mundo contemporáneo.

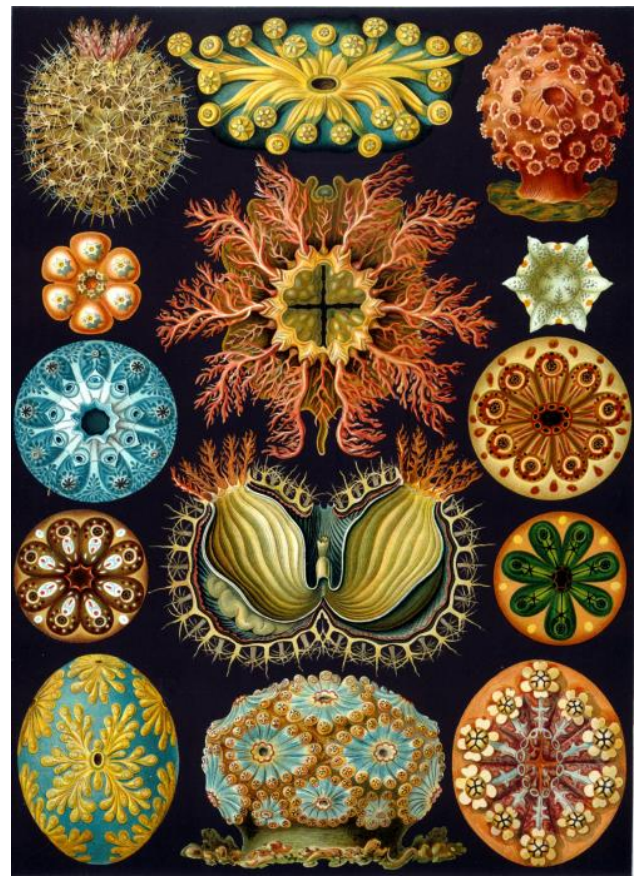

Imagen 12. Haeckel, E. (1904). Kunstformen der Natur. Recuperado de http://bildgeist.com/ernst-haeckelkunstformen-der-natur/ 
Estudios recientes abordan la importancia de los descubrimientos biológicos y su divulgación en el periodo de la guerra y en el final del conflicto (Botar, 2017). Proporciona una visión de la biología en la historia de la arquitectura moderna. En el periodo de la Bauhaus (1919-33) se extiende la filosofía y la ciencia del biocentrismo y su concepción de la biología basada en el funcionalismo. El uso de la biología en su relación con el arte y la arquitectura emergen históricamente del «biocentrismo», la noción decimonónica que ve el mundo natural definido en el sentido de Gestalt o de la vida como una totalidad de relaciones. A finales del siglo XIX Ernst Haeckel, conocido filósofo y biólogo, consiguió transmitir las imágenes de las estructuras formales de la naturaleza que se mostraron equivalentes a las creadas por las artes. Difundió imágenes de especies naturales a través de las multicolores muestras del microscopio. La iconografía biológica contenida en la obra de Haeckel Kunstformen der Natur (1904) - Formas artísticas de la Naturaleza - fue una fuente de inspiración de primer orden para los >comienzos de la abstracción (véase Imagen 12).

Esta vía de conocimiento podría dotar de bases ciertas a las leyes de la forma, que constituyeron la preocupación central en el debate de la Bauhaus desde su creación. El biocentrismo tenía bases diferenciadas en el darwinismo, el determinismo biológico, Nietzsche y la naturaleza materialista del romanticismo. Se autoproclamó el monismo, el neovitalismo y la visión ecológica del mundo. Algunos de sus divulgadores fueron lecturas frecuentes de Schlemmer, como Max Scheler, Oswald Spengler o Sigmund Freud, entre otros. Además, fue un miembro convencido del grupo de adeptos el principal promotor de la reforma educativa Gustav Wyneken o también Heinrich Jacoby. Adoptó la denominación de Jugendbewegung movimiento joven - y su principal divulgador fue Raoul Heinrich Francé, como epistemología objetiva y biocéntrica que dio a conocer en 1920 en Dresde en una sesión de la Sociedad Schopenhauer. Su visión de una armoniosa integración de todos los fenómenos conforme a la jerarquía de los ecosistemas se difundió a través de sus publicaciones científicas divulgativas bajo el título de Kosmos.

Así, la noción monista/holista/organicista del topos se asumió en la legión del profesorado de la Bauhaus como un lema que se puede encontrar en la totalidad de sus profesores, y particularmente en Schlemmer, cuya esposa Helena Tutein - Tut Schlemmer - se adhirió al grupo cuando estudiaba danza en Dresde, colaborando al propio tiempo en defensa del Grupo Espartaquista. Está constatado que Oskar Schlemmer asistió en 1920 
junto con Klee a una conferencia de Hans Prinzhorn sobre la mentalidad de los enajenados cerca de Stuttgart. Inmediatamente el científico recibió una invitación a impartir una conferencia en Weimar en abril de 1922, poco antes de la aparición de su libro Geisteskranken - Artisticidad de la Mente III-, que fue lectura habitual del profesor de teatro Lothar Schreyer. Y en el caso de Schlemmer, constituyó una versión profunda de misticismo vital del biocentrismo Haeckeliano que impregnó su actividad pedagógica y toda su obra.

El principal documento que revela esta visión totalizadora es el referido esquema realizado en las fechas de esta conferencia, contenido en el diario y que acabó teniendo algunas versiones posteriores hasta su publicación en Bauhaus no 2-3 (1928), 22: Der Mensch im Ideenkreis [El hombre y el círculo de las ideas].

En el proceso de aproximación a la figura humana, la experiencia personal de la guerra fue fundamental en el trabajo de Schlemmer. Su obra se proyectó sobre un cuerpo humano sin identidad, deshumanizado, alusión a la intemporalidad de los sujetos utópicos, que por ello no son vulnerables ni a los efectos físicos ni a los daños emocionales. El cuerpo sin emoción o desprovisto de individualidad, el sujeto inhumano, es también efectivamente un utópico cuerpo inmortal que contiene la fantasía de ser resistente al trauma, a la conmoción y a la muerte. Esta visión aparece en algunos personajes del mundo de la danza, y en particular en Schlemmer y en Rudolf von Laban, que conciben semejante cuerpo después de la guerra.

Schlemmer escribió de este radical «empeño para un hombre libre de su atadura física y aumentar su libertad de movimiento más allá de su potencial nativo en sustitución para el organismo de la figura humana mecánica». El cuerpo humano se convierte progresivamente en prótesis en su evolución física.

Así se produjeron las primeras imágenes de la futura Danza de los bastones, en la que unas extensiones celebran las posibilidades de conexión con el espacio mientras revelan los constreñimientos que hemos ingeniado para nosotros mismos (véase Imagen 13). En sus primeras versiones y trabajando por cuenta propia al terminar la Primera Guerra Mundial, los suplementos del cuerpo de Oskar Schlemmer amplifican las debilidades del cuerpo natural y lo mejoran. Esta danza está asociada a las visiones de las lesiones que contempló en sus dos ingresos hospitalarios. Más tarde, en $\mathrm{La}$ Danza de bastones 1 de 1927 usó un equipamiento diseñado para educación física para alargar las extremidades de los bailarines (véase Imagen 14). 
Por otra parte, los personajes del mencionado Ballet Triádico, ejecutado por primera vez en 1922, están obligados a formar parte de indumentarias escultóricas de gran peso y formas geométricas complejas. Esta prótesis imaginaria hacía olvidar la forma antropológica móvil que las accionaba, figuras mutantes de cualidades mecánicas (Slevn, 2015).
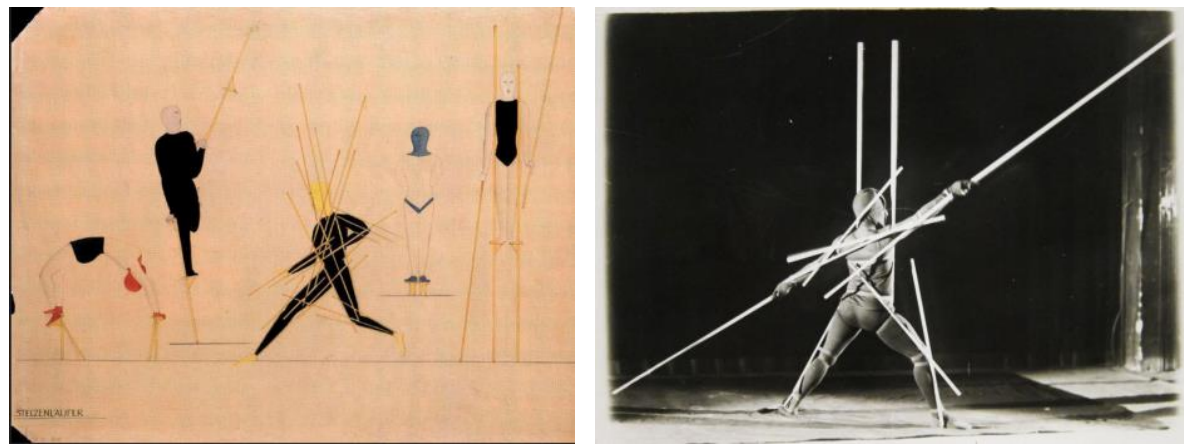

Imagen 13. Consemüller, E. (1927). Oskar Schlemmer: Danza de los bastones I. Recuperado de https://thecharnelhouse.org/2013/06/02/oskar-schlemmers-bauhauscostume-parties-1924-1926/-jp-carousel-9781

Imagen 14. Schlemmer O. (1927). Danza de los bastones. Boceto. Recuperado de https://www.metalocus.es/es/noticias/oskar-schlemmer-el-artista-del-baile-en-elpompidou-metz

En su diario, el 5 de julio de 1926, define las diversas disciplinas de la mecanización necesarias para la ejecución de su obra: una música mecánica producida por un organillo, y añadió como referencia a Heinrich von Kleist, autor de Teatro de marionetas (1810),

... estereotipia de la forma de danzar, condicionada en parte por el vestuario, ... fija los paralelos con el vestuario matemático, mecanicista... Además, la danza algo así como de marionetas estará más acorde con la música salida algo así como de una caja de música, ... Se podría argumentar que quizá los bailarines deberían ser puramente marionetas... o mejor que: formaran parte de un dispositivo de precisión totalmente mecánico, autoaccionado, casi sin intervención humana, a menos que fuera desde una mesa de control oculta... No es más que una cuestión de tiempo y de dinero el poder realizar un experimento de este tipo. (Schlemmer, 1987, pp. 88-89)

Schlemmer hace referencia en distintos pasajes de su diario y en el Bauhausbücher a la relación del teatro con el mundo de las apariencias, y 
reclamó la necesidad de poner de relieve su artificialidad, recordando a E.T.A. Hoffman en sus Piezas fantásticas (El perfecto maquinista, El autómata), que por su inhumanidad poseen perfección artística como comenta a su amigo Otto Mayer en 1921:

Tú ya has descrito a las máquinas como composiciones abstractas. Sin embargo, las máquinas deben su existencia no tanto a la abstracción como a consideraciones de orden puramente funcional. ¿Enseñan al arte como liberarse del romanticismo y ser concreto? Como Stendhal, que leyó el Código Civil y luego escribió sus novelas en un estilo factual, poco romántico. (Schlemmer, 1987)

En conjunto se reconocen una variedad de elementos mecánicos: marionetas, figuras, autómatas, clowns, bailarines, ... En todos los proyectos escénicos, performances, bailes y fiestas el espacio se proyecta como negativo del cuerpo y adquiere una dimensión interactiva, contando además con la necesaria extensión al espectador y a los medios de la imagen. En todos los proyectos escénicos se identifica la necesaria participación de las cámaras y de la iluminación como factores que intervienen en la acción.

En este contexto son especialmente significativas las versiones del Gabinete de figuras (véase Imagen 15) en sus versiones de 1921 y 1923 y su movimiento sobre un fondo negro y la variedad de objetos móviles sometidos a iluminación en las versiones más avanzadas hasta la multitudinaria presencia de toda clase de personajes en 1927, tal como recoge la revista de la Escuela en el número especial que le dedicó a las artes de la escena, y particularmente al conjunto de la obra de Schlemmer (Bauhaus, 1927). Las imágenes son reportajes fotográficos de los colaboradores habituales del taller, T. Lux Feininger, Erich Consemüller o Xanti Schawinsky.

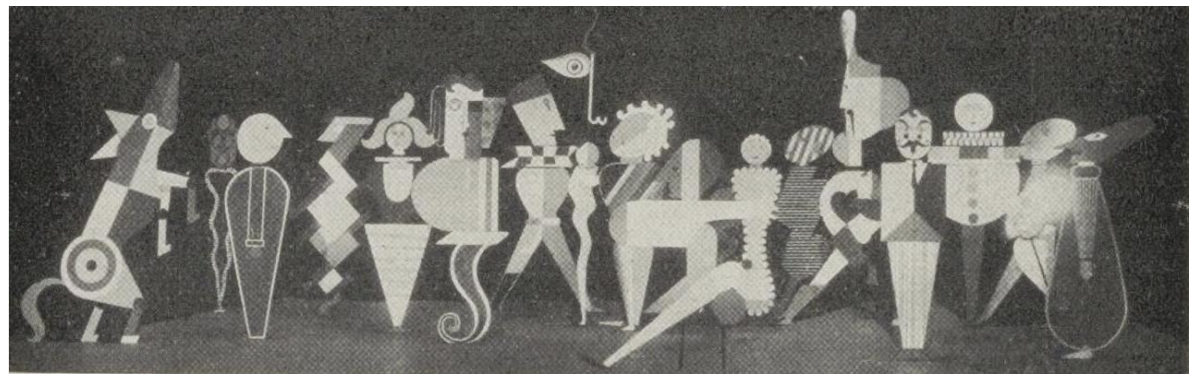

Imagen 15. Bauhaus 1-3 (1927). Gabinete de figuras. 
La serie de danzas de figuras, autómatas en mallas de colores y con máscaras metálicas presenta igualmente una serie de reportajes interesantes de carácter metafísico (véase Imagen 16). Sus ejecutantes, Kurt Schlemmer, Siedhoff y Kaminsky, ejecutan danzas de tres, con diversos aditamentos. Sirvan como ejemplos: Raumtanz — danza del espacio- o Formentanz danza de las formas-, en la que la geometría del suelo es invadida por figuras dotadas de bastones y esferas.

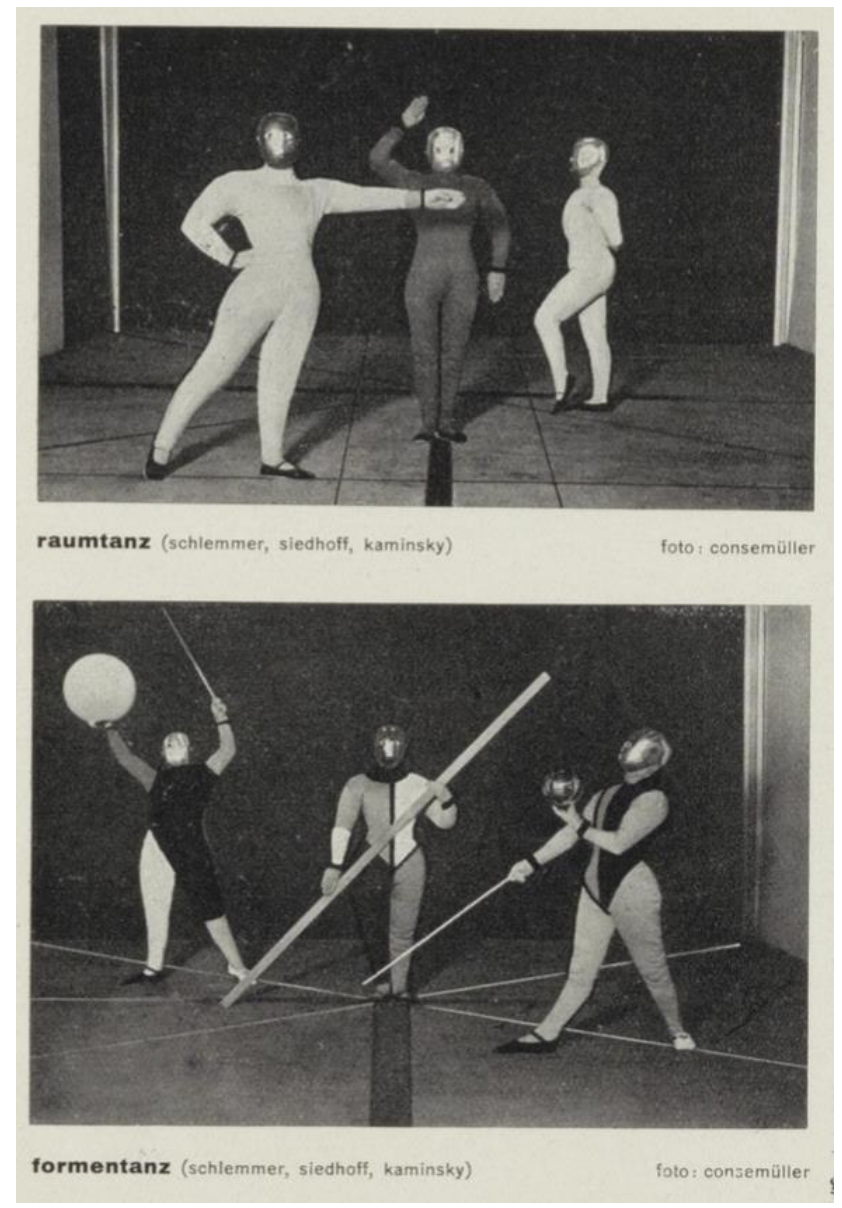

Imagen 16. Bauhaus 1-3 (1927). Danza del espacio y danza de las formas. 
Merece la pena destacar la relación de obras en las que la asistencia lumínica es parte de la concepción de la obra. Un caso especial es el de las performances concebidas tomando como motivo la figura humana. Es una modalidad de escultura viva, definida por la malla que cubre la totalidad del cuerpo del actante, en Figur im raum mit bodengeometrie und raumlinien Figura en el espacio con geometría en el suelo y líneas en el espacio- en un lugar abstracto en el que el escenario presenta un círculo atravesado por líneas luminosas en el cruce de los diámetros longitudinal y transversal. Unos cables proyectados desde el techo simulan el contexto de un cono sobre la figura ubicada en el centro de la geometría definida por la luz. En sentido similar, la acción Raumlineatur mit figur — Red de líneas en el espacio con figura- (véase Imagen 17), y precisa de la colaboración de la fotografía a través de varias exposiciones simultáneas que permiten contemplar la escultura viva contenida en la funda de tejido blanco que la cubre completamente.

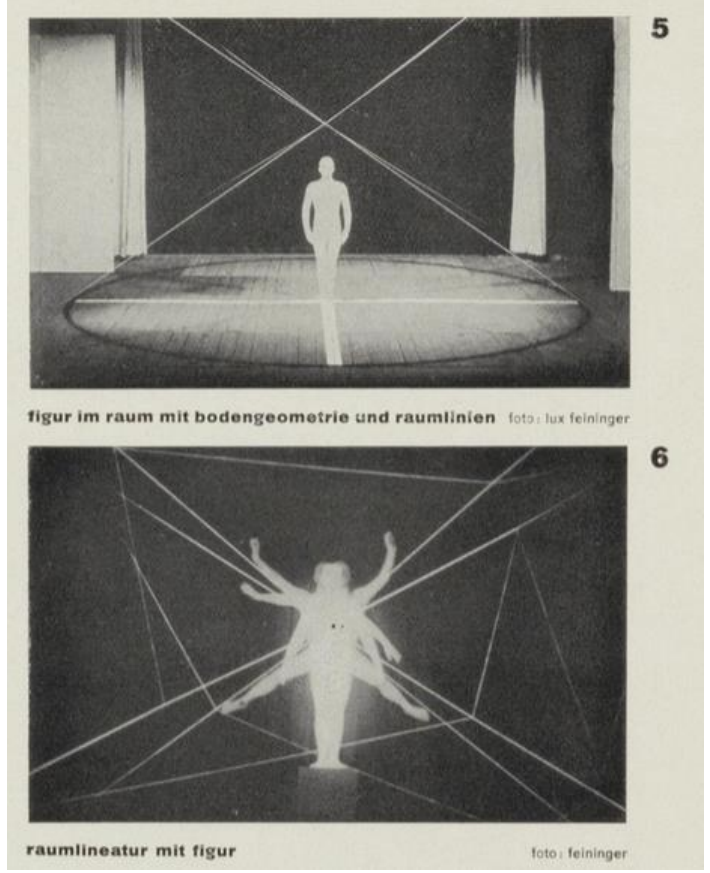

Imagen 17. Bauhaus 1-3 (1927). Red de líneas en el espacio con figura. 
El reportaje realizado por Erich Consemüller en las dos imágenes de la mímica realizada por tres figuras enmascaradas, también cubiertas con mallas, muestra los dos movimientos: el gesto inmóvil Vorhang- und bewegungsstudien - cortina y estudios de movimiento- y Stadien dramatischer gestik —estadio de gesticulación dramática- en la que se hacen visibles las evoluciones de las figuras en este espacio y los efectos de la sombra proyectada por efecto de los focos. El diagrama de la Danza de los gestos incluida en esta síntesis de la investigación teatral de la Bauhaus traduce el conocimiento de los estudios de coreografía, como disciplina conceptual con aplicaciones geométricas y matemáticas.

Algunas acciones de origen tradicional, mezcla de gimnasia, mímica, esgrima, se transformaban por efecto de los dispositivos alusivos a la geometría del hombre como centro de todas las cosas, la imagen renacentista interpretada a propósito de los comentarios de Vitruvio, de las que sobresale la muy conocida imagen de Leonardo da Vinci. Como en las versiones de figuras en el espacio, una red lineal construye una geometría para hacer visible la abstracción metafísica de la escena con ejecutantes enmascarados o portadores de aros. Es el caso de la Equilibristik ejecutada por Loew, Hildebrandt, Lou Scheper, Siedhoff y Weininger, fotografiados de nuevo por Consemüller (véase Imagen 18).

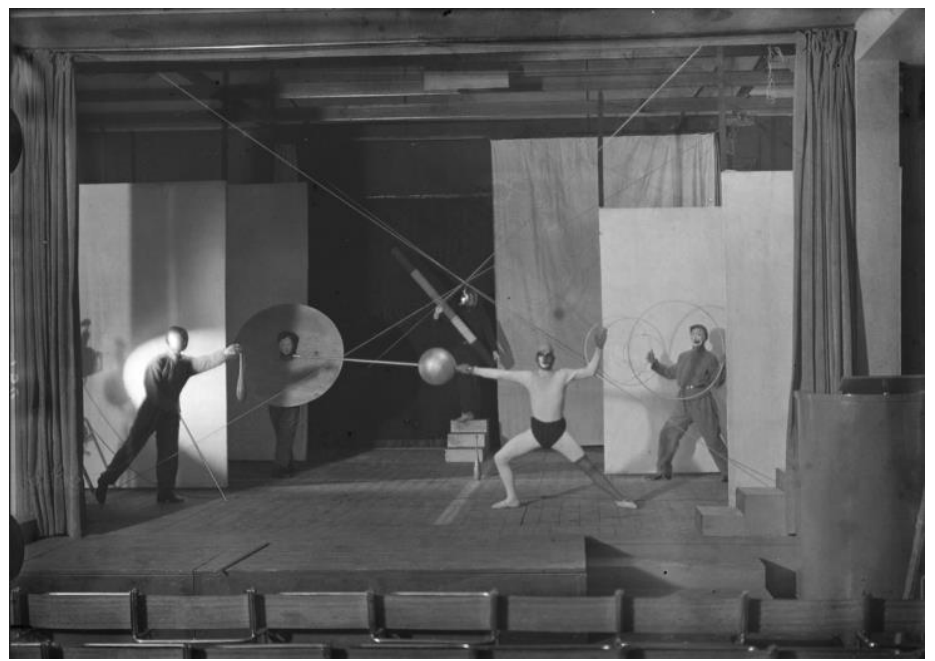

Imagen 18. Consemüller, E. (1927). Oskar Schlemmer, Equilibrística. Bauhaus 1-3 (1927). 
Y especialmente son complejas acciones conscientes del mundo abstracto y mecanizado en el que el hombre es un trágico figurante las que cuentan con paneles sometidos a la acción de la luz, como Lichtspiel mit projektion und transparenz - espectáculo de luz con proyección y transparencia, presentación equilibrada de las sensaciones provocadas por las formas sometidas a la acción de la luz (véase Imagen 19). Más compleja Aus einer pantomime mit figuren und transparenten wäden - De una pantomima con figura y paredes transparentes-, ejecutada por Lou Scheper y Siedhoff, y fotografiada por Feininger. La sucesión de paneles y las figuras recortadas provocan un efecto paradójico. Los contrarios suscitan mecanismos de extrañamiento (véase Imagen 20).

Finalmente, en la Metalltanz — danza de metal- ejecutada por Karla Grosch, e iluminada por el propio Schlemmer, los efectos lumínicos reflejados por el fondo metálico sometido a ondulaciones provocan un espectacular efecto en la toma realizada por Erich Consemüller (Bauhaus, 1927) (véase Imagen 21).
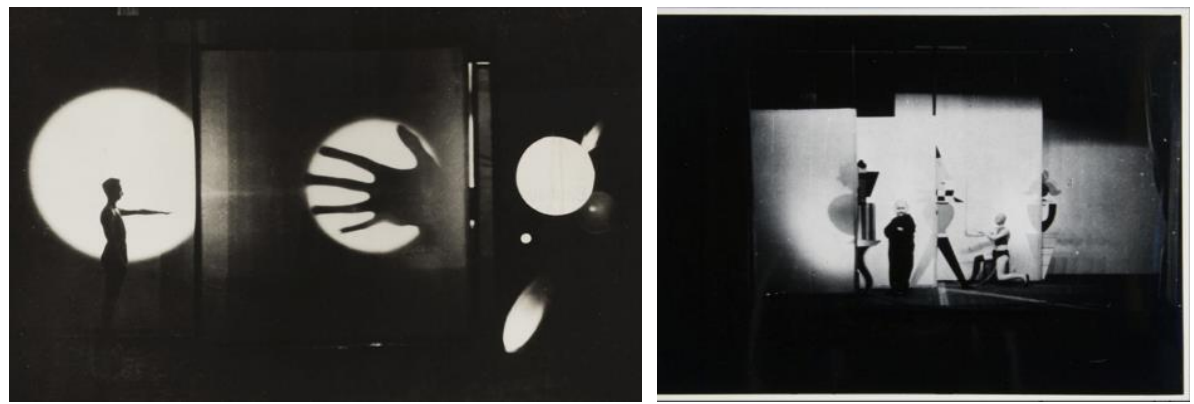

Imagen 19. Feininger. T. L. (1927). Lichtspiele (Lichtspiel mit Projektion und Transparenz: Werner Siedhoff). [gelatina de plata, 20,3 x 25,5 cm.]. Bauhaus 1-3. Recuperado de https://www.kunstarchive.net/en/wvz/t_lux_feininger/works/_6246/type/all

Imagen 20. Feininger T. L. (1927). Oscar Schlemmer: "Gabinete de figuras" en la Bauhaus, Bauhaus 1-3 (1927). Bauhaus-Archiv/Museum für Gestaltung. [Gelatina de plata, 5,3 x 9,5 cm.]. Recuperado de https://www.kunstarchive.net/de/wvz/t_lux_feininger/works/zwei_taenzer_lou_scheper_und_werner_s iedhoff_und_drei_flache_figurinen_aus_schlemmers_figuralem_kabinett/type/all 


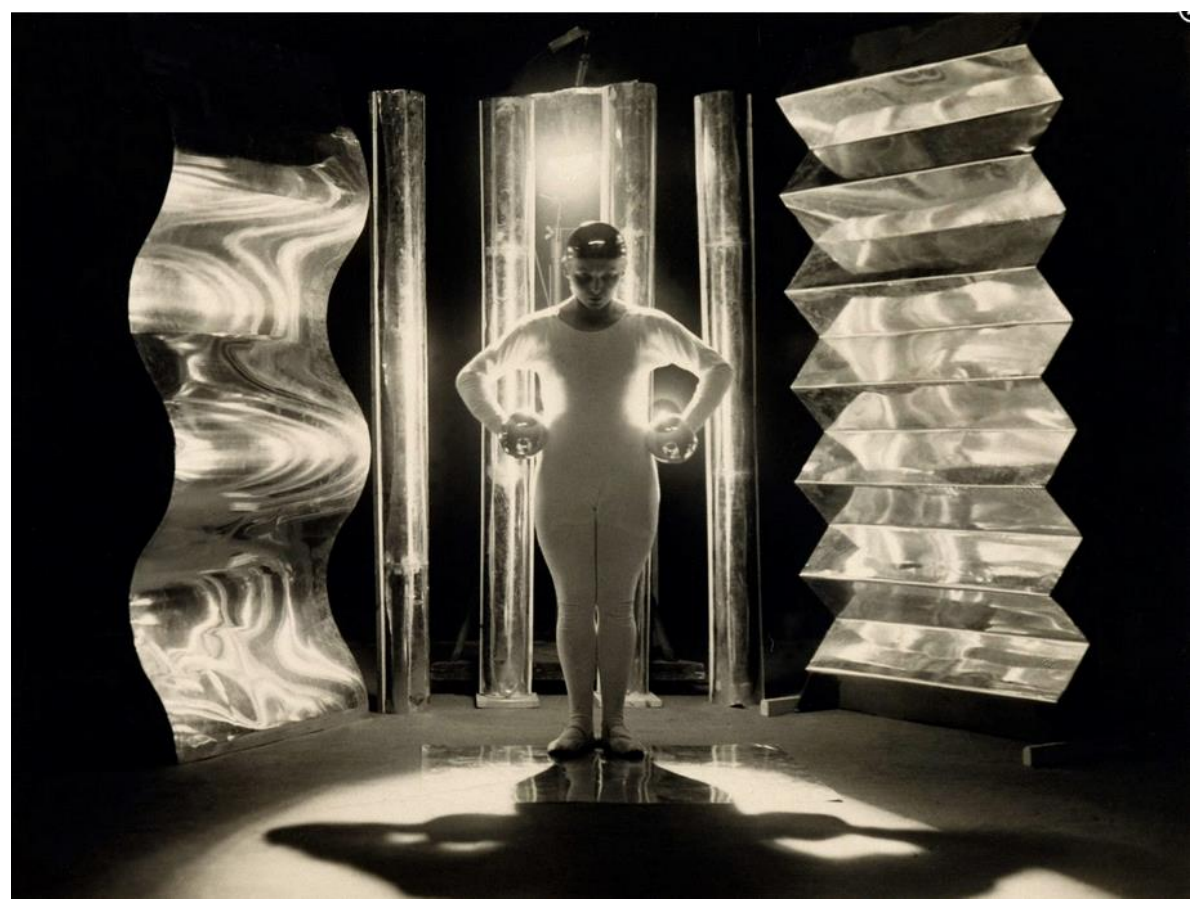

Figura 21. Feininger, T.L. (1927). Oskar Schlemmer: Karla Grosch. Danza del metal. Bauhaus 1-3.

\section{Referencias}

AA.VV. (2011). Danser sa vie. Paris: Centre Pompidou, noviembre de 2011-abril de 2012. Recuperado de http://www.detambel.com/images/30/revue_451.pdf

Bauhaus (1927). $\mathrm{n}^{\mathrm{o}}$ 1-3. Reportajes fotográficos de los colaboradores habituales del taller, T. Lux Feininger, Erich Consemüller y Xanti Schawinsky.

Botar, O. (2017). «1. The Biocentric Bauhaus», en Terranova Charissa N. y Tromble, Meredith (eds.). The Routledge Companion to Biology in Art and Architecture. New York: Routledge.

Enrile Arrate, J. P. (2016). Teatro relacional: una estética participativa de dimensión política (Tesis Doctoral inédita). Universidad Complutense, Madrid. 
De Michelis M. y Kohlmeyer A. (a cura di). (1996). Bauhaus 1919-1933: da Klee a Kandinsky, da Gropius a Mies van der Rohe. [Catálogo] Milano: Mazzotta. Exposición Fondazione Antonio Mazzotta, Milán de 19 octubre 1996 a 9 febrero 1997.

Flocon, A. (1987). Scénographies au Bauhaus Dessau 1927-1930: Hommage à Oscar Schlemmer en plusieurs tableaux. Paris: Atelier du Nombre d'Or.

Gropius, W. y Wensinger, A. (eds.). (1961). Oskar Schlemmer, László Moholy-Nagy y Farkas Molnár: Theater of the Bauhaus. MiddletonCT: Wesleyan University Press.

Maiakovski, V. (1972). Vladimir Maiakovski o La rebelión de los objetos. Madrid: Editorial Fundamentos.

Pastor Prada, R. (2012). Artes plásticas y danza: propuesta para una didáctica interdisciplinar (Tesis Doctoral Inédita). Universidad Complutense de Madrid, Madrid.

Schiller, F. (1990). Cartas sobre la educación artística del hombre (1795). Barcelona: Anthropos.

Schlemmer, O. (1969). Der Mensch. Mainz: Florian Kupferberg Verlag Schlemmer, T. (ed.). (1987). Oskar Schlemmer. Briefe und Tagebücher [Oskar Schlemmer. Cartas y diarios]. Madrid: Paidós estética.

Sina, A. (dir.). (2011). Feminine futures: Valentine de Saint-Point: performance, danse, guerre, politique et erotisme. Dijon: Presses du Réel.

Slevn, T. (2015). Visions of the Human: Art, World War One and the Modernist Subject. London-New York: I. B. Tauris.

Watson, P. (2014). The Age of Atheists. How we Have Sought to Live Since the Death of God. New York-London-Toronto-Sidney-New Delhi: Simon \& Schuster. Recuperado de https://archive.org/details/TheAgeOfAtheists 
186 Maisa Navarro - La Performance y los Laboratorios de la Utopía

Maria Isabel (Maisa) Navarro Segura: Catedrática de Historia del Arte.

Facultad de Humanidades. Universidad de La Laguna.

Angélica Camerino Parra: Doctoranda e Investigadora en Historia del Arte. Universidad de La Laguna.

Email address: minavarr@ull.edu.es y acamerin@ull.edu.es

Web: https://www.ull.es/departamentos/historia-del-arte-filosofia/personal/

Contact Address: Facultad de Humanidades-Sección de Geografía e Historia. Universidad de La Laguna. C/ Prof. José Luis Moreno Becerra, s/n., 38200 San Cristóbal de La Laguna-Tenerife, Canarias. Apartado 456. 